\title{
Research and Development of the Tension Pay-Off Equipment for Wire Rope Maintenance
}

\author{
W.H. Cui, L. Tang, C. Fu \\ School of mechanical engineering \\ University of Jinan \\ Jinan, China, 250022
}

\author{
K.Q. Gong \\ Shandong Electrical Power Supply \& Transformation \\ Engineering Co., Ltd \\ Jinan, China, 250118
}

\begin{abstract}
Traction wire rope is used in the construction of the power. The wipe rope cleaning, inspection and maintenance integration system can detect the damages on the traction wire ropes and maintain the ropes. The integration system consists of a variety of equipments and the tension pay-off equipment is one of them. According to the role of the tension pay-off equipment in the integration apparatus, the functional requirements of the equipment were determined and the structure of the equipment was designed. This paper used SolidWorks to build a three-dimensional model of the tension pay-off equipment and did finite element analysis of its key components with COSMOS Works. The structural optimizations and improvements about the tension pay-off equipment were carried out according to the results of the analysis. The tension pay-off equipment has been put into use and it works well.
\end{abstract}

Keywords-Wire rope maintenance; Tension pay-off; Finite element analysis; Structural optimization

\section{INTRODUCTION}

Wire rope used for tension stringing work in relatively poor conditions, it easily produce wire rope wear, fatigue, broken wires, corrosion and deformation, thereby reduce the strength of the wire rope and shorten the service life of the wire rope, easily lead to accidents of construction[1-2]. According to DL/T1079-2007 "Twist Proof Steel Wire Ropes for Line Stringing Under Tension in Overhead Transmission Line”, wire rope used for tension stringing should be regularly cleaned, tension detection, oil maintenance and other measures every year. "environment-friendly wire rope cleaning, detecting and maintaining integrated system” is a company research project, it is referred to as "wire rope maintenance line", and its solution is shown in Figure 1. The maintenance line can complete the detection and maintenance for traction wire rope of the tension stringing work, to ensure the Safety of tension stringing construction. The tension pay-off equipment (hereinafter it is referred to as tensioner) belongs to a part of the maintenance line.

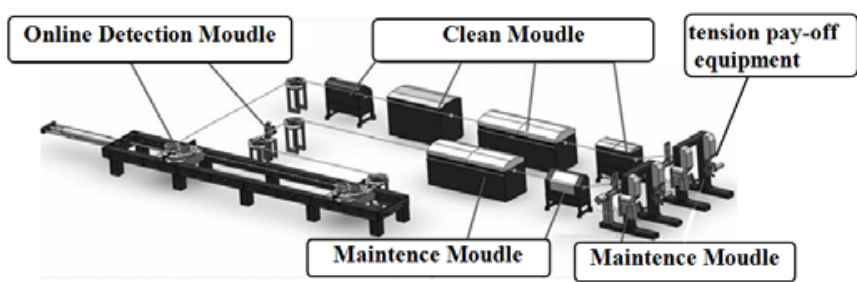

FIGURE I. ENVIRONMENT-FRIENDLY WIRE ROPE CLEANING, DETECTING AND MAINTAINING INTEGRATED SYSTEM.

According to the data access[3-4], the existing tensioner are not suitable for the wire rope maintenance line. Therefore, in this paper, according to the demand of the wire rope maintenance line, the design and improvement of tension pay-off machine are processed the objective is to develop a suitable tensioner for the wire rope maintenance line, and ensure the reasonableness of the design and use of safety.

\section{Structural DeSIGN OF THE TENSIONER}

\section{A. Functional Requirements}

In the maintenance of the ropes, the ropes undergoes dirt brushing, soaking, cleaning, drying, grease immersion and rope collection after being unwound from the rope plates. The wipe rope cleaning, inspection and maintenance integration apparatus has traction equipment and the tensioner doesn't need to provide power. The tensioner should have the following functions. (1) The clamping of the rope plate. (2) The lifting of the rope plate. (3) The applying of a tension to the wire rope. (4) The fixing of the rope expanding direction.

\section{B. Structural Design of the Tensioner}

In summary, the tensioner consists of frame, clamping mechanism, lifting mechanism, braking mechanism and rope arrangement mechanism. The general structure of the tensioner is shown in Figure 2. The braking device uses magnetic powder brake as the braking tool. The tension can be easily controlled with the magnetic powder brake and this provides conditions for automatic, coordinated control of the entire wipe rope cleaning, inspection and maintenance integration apparatus. To ensure the smooth passage of the joints, the rope arrangement mechanism uses a spring structure. 


\section{FINITE ELEMENT ANALYSIS AND STRUCTURAL} OPTIMIZATION ABOUT KEY COMPONENTS OF THE TENSIONER

\section{A. Analysis of Tensioner Working Conditions}

Tensioner provides a tension to the wire rope to ensure the rope hold taut during maintenance. The tensioner's working principle is: Firstly, the brake device (with brake core clamper) and clamping device (with clamping core clamper) work together to clamp the rope plate. Secondly, the lifting mechanism enhance the rope plate some distance off the ground and the control system controls the magnetic brake to provide a stopping power that based on the size of traction power. Then, the brake spindle and shifting fork act on the rope plate and a tension will generate in the rope.

The brake core clamper (with shifting fork) is an important working mechanism foe it not only provides the necessary brake tension, but also bears the weight of the rope plate. As the transmission and weight bearing part, the spindle in the brake core clamper bears the twisting and bending moments. The spindle also bears cycle bending moments during the rotation of the rope plate. The performance of the spindle will directly affect the working of the tensioner. The core clamper slide carriage connects the brake core clamper and the lifting mechanism. The structure and force condition of the slide is complex. There is no analytical solution to the stress and strain that the slide bears. In summary, the spindle and the slide carriage are the key parts affecting the performance of the tensioner.

The tensioner's three-dimensional model built by SolidWorks is shown in Figure 3.

\section{B. Finite Element Simulation Tool Selection}

COSMOSWorks is fully integrated in the design and analysis system of SolidWorks [5-6]. It provides a complete means of analysis for design engineers. This paper chooses COSMOSWorks as the finite element analysis tool.

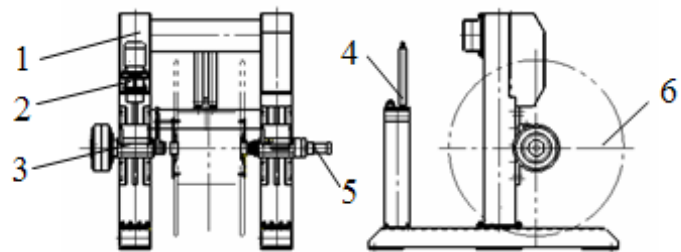

1-frame 2-lifting mechanism 3- magnetic powder braking mechanism 4- rope arrangement mechanism 5-clamping mechanism 6-rope plate

FIGURE II. THE TENSIONER.

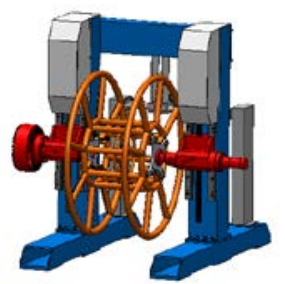

FIGURE III. THREE-DIMENSIONAL MODEL OF THE TENSIONER.

\section{Finite ElEMENT ANALysis AND StRUCtURAL}

\section{A. Optimization about the Spindle}

The simplified model of the brake mechanism is shown in Figure 4. In the model, the magnetic brake, core clamper slide, bearings and so on are removed and it mainly consists of spindle, key and shifting fork. The spindle is connected with the shifting fork by the key. Brake torque generated by the spindle passes to the shifting fork through the key. The shifting fork acts on the rope plate and applies brake torque to the plate. The structure of the spindle is shown in Figure 5.

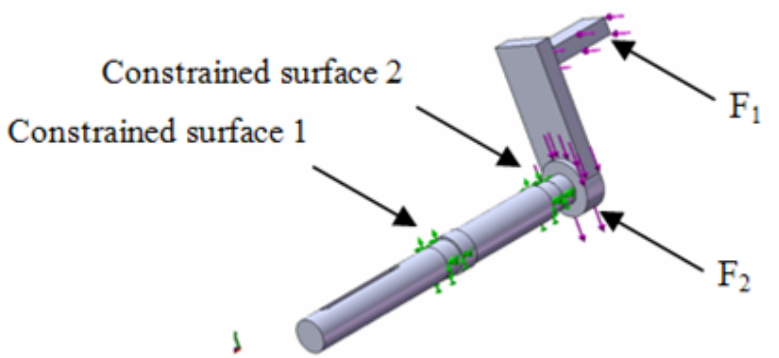

FIGURE IV. SIMPLIFIED MODEL OF THE BRAKE MECHANISM.

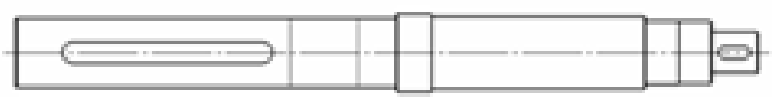

FIGURE V. STRUCTURE OF THE SPINDLE.

The spindle is supported on the core clamper slide carriage by bearings installed on constrained surface 1 and constrained surface 2 . In the simulation analysis, constraints will be fixed at constrained surface 1 and constrained surface 2. The force F1 exerted on the shifting fork is determined to $2400 \mathrm{~N}$ based on the maximum tension in the rope and the diameter of the rope plate. The weight of the rope plate is endured by two spindles and each spindle bears half of the weight. The gravity of the rope plate is $16000 \mathrm{~N}$ and each spindle will bear $8000 \mathrm{~N}$. The constraints and forces applied to the brake mechanism are shown in Figure 3. The safety factor distribution map obtained by simulation is shown in Figure 6. The minimum safety factor at the key connection is 0.2599 . It means there are serious safety hazards in the spindle and the design doesn't meet the requirements. The red region is the area where the safety factor is less than 1.

To ensure the safety of the brake mechanism torque transmission, the torque transfer mode must be radically improved. As shown in Figure 7, the structure of the spindle segment where bears the force is changed and the key connection is removed. The improved spindle can greatly enhance the torque transfer capacity. And keep the diameter of the spindle segment invariant and optimize the section distance. In the optimization, the optimization constraint is that the minimum safety factor should be bigger than 1.5 and the optimization objective is to minimize the weight of spindle. The optimization results are shown in Table 1. 


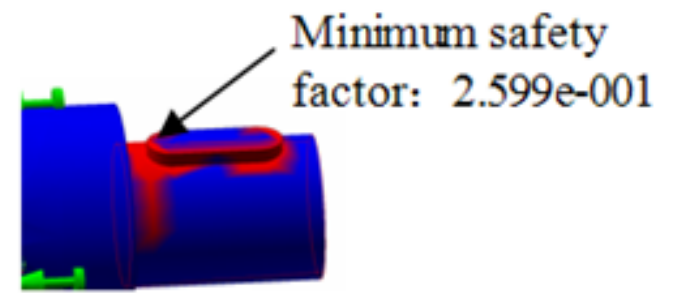

FIGURE VI. SPINDLE FINITE ELEMENT ANALYSIS CLOUD

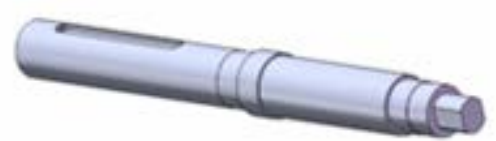

FIGURE VII. IMPROVED SPINDLE STRUCTUR E

TABLE I. COMPARISON OF PARAMETERS THAT BEFORE AND AFTER THE OPTIMIZATION.

\begin{tabular}{c|c|c}
\hline & $\begin{array}{c}\text { The initial } \\
\text { values }\end{array}$ & $\begin{array}{c}\text { Values after } \\
\text { comparison }\end{array}$ \\
\hline $\begin{array}{c}\text { Section distance } \\
\text { (mm) }\end{array}$ & 30 & 32 \\
\hline $\begin{array}{c}\text { Minimum safety } \\
\text { factor }\end{array}$ & 1.39 & 1.53 \\
\hline Minimum weight (g) & 1730 & 1752 \\
\hline
\end{tabular}

V. Finite ELEMENT ANALYSIS AND STRUCTURAL OptimizATION ABOUT THE CORE ClAMPER SLIDE CARRIAGE

According to the tensioner's working condition and the previous design experience, the minimum safety factor of the core clamper slide carriage (hereinafter it is referred to as slide) takes 6 . The three-dimensional model of the preliminarily designed core clamper slide is shown in Figure 8.

Set the material of the slide to HT200. According to the slide's force condition, impose fixed constraints to the surface at where the slide contacts with the turnbuckle, impose sliding constraints to the surfaces at where the slide contact with the guide rail and apply downward a force which is $1200 \mathrm{~N}$ to where the bearings support the slide. Mesh the slide model and do the static analysis. The safety factor distribution map is shown in Figure 9. The minimum safety factor of the slide is 12.31 and the maximum stress appears at the surface where the slide contacts with the turnbuckle. The simulation analysis shows that the structural performance is far greater than the design requirements.

Figure 9 shows that stress at the slide's thread, through which the slide connects with the screw, is larger than other parts of the slide. The above and behind parts of the slide almost bear no force. Parts with a relatively larger potential of optimization can be found through Figure 9. This paper will optimize the dimensions and shapes of these parts.

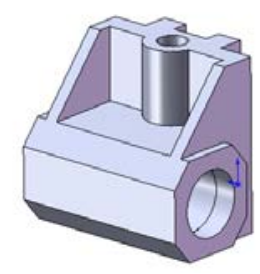

FIGURE VIII. THE MODEL OF THE SLIDE.

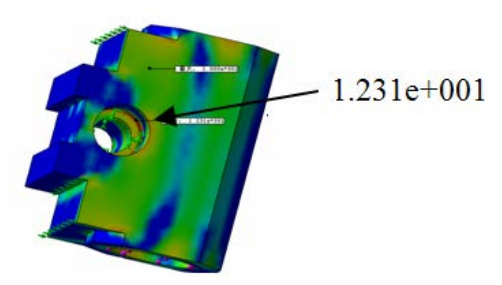

FIGURE IX. THE SAFETY FACTOR DISTRIBUTION MAP OF THE SLIDE.

The optimization purpose of this paper is to reduce the weight of the slide on the basis ensuring the slide's structural strength and stiffness. Take the slide's weight as the optimization goal. Parts that bear the most force are the spindle hole and the thread. Take the wall thickness shown in Figure 10 as the optimization parameter. The optimization results: the wall thickness is reduced from $35 \mathrm{~mm}$ to $20 \mathrm{~mm}$ and the minimum safety factor is reduced from12.3 to 10 . Parameters before and after the optimization are compared in Table 2.

TABLE II. COMPARISON OF PARAMETERS THAT BEFORE AND AFTER THE OPTIMIZATION.

\begin{tabular}{l|c|c}
\hline & $\begin{array}{c}\text { The initial } \\
\text { values }\end{array}$ & $\begin{array}{c}\text { Values after } \\
\text { comparison }\end{array}$ \\
\hline Wall thickness $(\mathbf{m m})$ & 35 & 20 \\
\hline Minimum safety factor & 12.31 & 10 \\
\hline Minimum weight $(\mathbf{g})$ & 6819 & 5985 \\
\hline
\end{tabular}

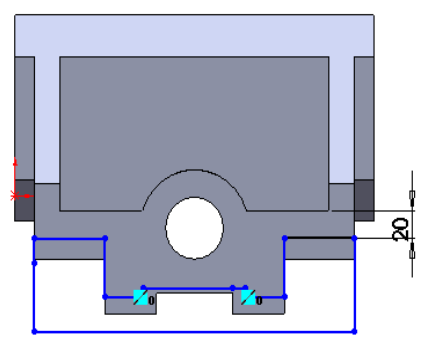

FIGURE X. THE SLIDE’S OPTIMIZATION PARAMETER.

\section{CONCLUSION}

This paper designed the tension pay-off machine based on the tensioner's work condition and function requirements. In order to ensure tensioner's design rationality and safety, this paper made the finite element simulation analysis about the key parts of the tensioner. The structures of these parts were optimized based on the simulation results. The tension pay-off machinet has been put into use in a company and it works well. 


\section{REFERENCES}

[1] Yun Sun, Hong-xue Chen, Dong-yao Shu, Hubei Electric Power. 34(2010) 79-81.

[2] Fang-mao Kang, Coal Mirie Machinery. 30(2009) 154-156.

[3] Hai-ping Jiang, Tension Stringing Equipment and Application, China Electric Power Press Beijing, 2005.

[4] Hai-ying Cui. Electric Wire \& Cable. 6 (2003) 45-46.

[5] Yan-ping Yao, Lei Qi, Hong-fu Yue. Hoisting and Conveying Machinery. 12 (2012)47-50.

[6] Lei Qi, Zhi-de Zhang, Hao Wen, Gang Han. Hoisting and Conveying Machinery. 4 (2011) 30-33. 